\title{
Comparison of Two Mathematical Models for Greenhouse Gas Emission from Membrane Bioreactors
}

\author{
G. Mannina ${ }^{(\bowtie)}$ and A. Cosenza \\ Dipartimento di Ingegneria Civile, Ambientale Aerospaziale dei Materiali, \\ Università di Palermo, Viale delle Scienze, Ed. 8, 90100 Palermo, Italy \\ \{giorgio.mannina, alida.cosenza\}@unipa.it
}

\begin{abstract}
In this study two mathematical models (Model I and Model II), able to predict the nitrous oxide $\left(\mathrm{N}_{2} \mathrm{O}\right)$ and carbon dioxide $\left(\mathrm{CO}_{2}\right)$ emission from an University Cape Town (UCT) - membrane bioreactor (MBR) plant, have been compared. Model I considers the $\mathrm{N}_{2} \mathrm{O}$ production only during the denitrification. Model II takes into account the two ammonia-oxidizing bacteria (AOB) formation pathways for $\mathrm{N}_{2} \mathrm{O}$. Both models were calibrated adopting real data. Results highlight that Model II had a better capability of reproducing the measured data especially in terms of $\mathrm{N}_{2} \mathrm{O}$ model outputs. Indeed, the average efficiency related to the $\mathrm{N}_{2} \mathrm{O}$ model outputs was equal to 0.3 and 0.38 for Model I and Model II respectively.
\end{abstract}

Keywords: WWTP $\cdot \mathrm{N}_{2} \mathrm{O}$ modelling $\cdot$ Nutrient removal $\cdot$ Greenhouse gases

\section{Introduction}

During the last years, the attention on wastewater treatment plants (WWTPs) as sources of greenhouse gases (GHGs) (e.g., carbon dioxide, $\mathrm{CO}_{2}$, nitrous oxide, $\mathrm{N}_{2} \mathrm{O}$, and methane, $\mathrm{CH}_{4}$ ) has considerably increased. Among the GHGs produced by WWTPs, $\mathrm{N}_{2} \mathrm{O}$ is the most environmentally hazardous due to its strong global warming potential (GWP) (298 higher that $\mathrm{CO}_{2}$ ) and its capacity to deplete the stratospheric ozone layer (IPCC 2007).

An accurate quantification and mitigation of $\mathrm{N}_{2} \mathrm{O}$ emissions is imperative for an environmental protection. With this regard, the adoption of mathematical models allows to select designing or operating choices aimed at reducing the total amount of GHG emissions from WWTPs.

Several efforts have been performed in literature for establishing the best tool to predict/quantify GHG (Mannina et al. 2016; Spérandio et al. 2016; Pocquet et al. 2016). However, the $\mathrm{N}_{2} \mathrm{O}$ estimation is still the major crucial aspect in GHG modelling since its formation mechanisms are still under review (Ni et al. 2015). Current knowledge on $\mathrm{N}_{2} \mathrm{O}$ emissions suggests that it can be produced both during nitrification and denitrification processes (Kampschreur et al. 2011). Furthermore, autotrophic ammoniaoxidizing bacteria (AOB) can contributes to $\mathrm{N}_{2} \mathrm{O}$ production by means of two pathways: i. the nitrifier denitrification (ND) pathway, where $\mathrm{N}_{2} \mathrm{O}$ represents the terminal product 
of nitrite reduction ( $\mathrm{Law}$ et al. 2012); ii. the incomplete hydroxylamine $\left(\mathrm{NH}_{2} \mathrm{OH}\right)$ oxidation (NN) pathway, where $\mathrm{N}_{2} \mathrm{O}$ is an intermediate product during the $\mathrm{NH}_{2} \mathrm{OH}$ oxidation (Pocquet et al. 2016). With this regard, literature suggests that mathematical models that include both AOB contribution pathways reproduce well the measured data (Peng et al. 2015). However, this knowledge has been acquired on conventional activated sludge systems (CAS) often using short-term data (Ni et al. 2013b). Very few studies have been performed for integrated membrane bioreactor (MBR) models where physical separation processes and biological processes affecting the membrane fouling (e.g., soluble microbial products - SMP - formation/degradation) have to be included jointly. Specifically, Mannina and Cosenza (2015) have proposed an integrated ASM2d-SMP-GHG model (Model I) able to predict the $\mathrm{N}_{2} \mathrm{O}$ and $\mathrm{CO}_{2}$ emission from an University Cape Town (UCT) - MBR plant. Mannina and Cosenza (2015) consider the $\mathrm{N}_{2} \mathrm{O}$ production only during the denitrification according to the approach of Hiatt and Grady (2008). A new integrated MBR model including the two AOB formation pathways for $\mathrm{N}_{2} \mathrm{O}$ has been recently proposed by Mannina and Cosenza (2017) (namely, ASM2d-SMP-GHG-2P-AOB) (Model II). The purpose of this study was to compare the two models (i.e., Model I and Model II) for GHG emissions from MBR.

\section{Materials and Methods}

\subsection{Mathematical Models Description}

Both Model I and Model II are divided in two sub-models (physical and biological). The physical sub-model describes the key processes occurring during membrane physical separation, including membrane fouling (involving 6 model factors and 2 state variables). Regarding, the biological sub-models they are based both on the ASM2d and they include the SMP formation/degradation processes (Jiang et al. 2008; Henze et al. 2000). Furthermore, both models take into account $\mathrm{CO}_{2}$ as state variable according to the continuity-based model interface as proposed by Vanrolleghem et al. (2005). Despite the aforementioned similarities, the biological sub-models are deeply different. Indeed, Model I employs the Hiatt and Grady (2008) approach for $\mathrm{N}_{2} \mathrm{O}$. Consequently, Model I considers the two-step nitrification process (involving AOB and nitrite oxidizing bacteria, NOB) and the four step denitrification process. Furthermore, the $\mathrm{N}_{2} \mathrm{O}$ is modelled as an intermediate product during the heterotrophic denitrification (see further details in Mannina and Cosenza 2015). Conversely, Model II considers the $\mathrm{N}_{2} \mathrm{O}$ formation due both to heterotrophic and autotrophic biomass. In particular, regarding the autotrophic, Model II describes $\mathrm{N}_{2} \mathrm{O}$ formation during nitrification combining the two major AOB formation pathways, according to the approach presented by Pocquet et al. (2016). In Model II, $\mathrm{N}_{2} \mathrm{O}$ formation during the heterotrophic denitrification is described as in Model I.

Finally, regarding the stripping of $\mathrm{N}_{2} \mathrm{O}$ and $\mathrm{CO}_{2}$ gas both Model I and II employ an algorithm based on the diffusion coefficients (Mannina and Cosenza 2015).

Model I involves 24 state variables and 109 model factors (stoichiometric, kinetic, fractionation and physical factors). While, Model II involves 25 state variables and 116 model factors. 


\subsection{Models Application and Calibration}

Each model has been applied to a pilot plant with a UCT- MBR scheme treating $20 \mathrm{~L} \mathrm{~h}^{-1}$ of real wastewater. For the models calibration an innovative calibration protocol was employed (Mannina et al. 2011). This innovative calibration protocol is based on a step wise calibration with respect to a group of model outputs. With this regard, model calibration has been carried out considering a long term monitoring data set. The selection of the model factors to be calibrated has been performed by applying the Standardized Regression Coefficient (SRC) method (Saltelli et al. 2004).

\subsection{Criteria for Comparison}

Both models were compared by calculating model efficiencies on the basis of measured and simulated data. Specifically, it has been calculated the efficiency of each model output $\left(\mathrm{E}_{\mathrm{i}}\right)$ (exponential equation, $\mathrm{E}_{\mathrm{exp}}$ ) and the total model efficiency $\left(\mathrm{E}_{\mathrm{MOD}}\right)$ (Mannina et al. 2011). Four coefficients have been adopted to quantify the goodness of model response: $\mathrm{E}_{\text {exp }}$, the root mean squared error (RMSE), the Nash and Sutcliffe efficiency (N\&S) (Nash and Sutcliffe 1970) and the determination coefficient, $\mathrm{R}^{2}$.

\section{Results and Discussion}

For sake of conciseness, only the results related to the $\mathrm{N}_{2} \mathrm{O}$ model outputs (both dissolved and off-gas concentration within each reactor of the UCT-MBR pilot plant) will be here presented and discussed.

Figure 1a shows the results of the average, maximum and minimum efficiency (calculated adopting the exponential expression) obtained during the calibration process for the dissolved and off-gas $\mathrm{N}_{2} \mathrm{O}$ model outputs and for each model.
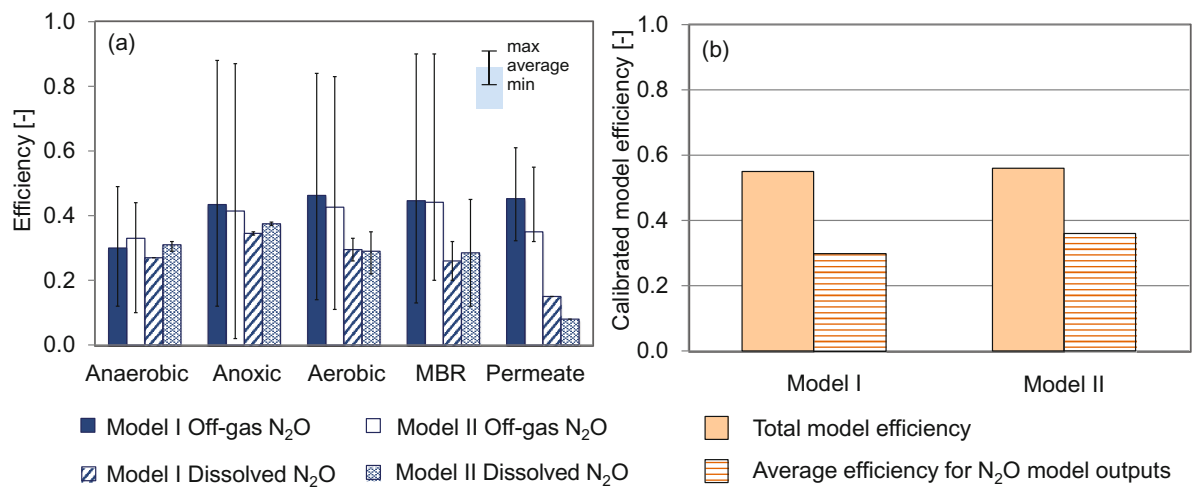

Fig. 1. Average, maximum and minimum efficiency (exponential expression) for dissolved and off-gas $\mathrm{N}_{2} \mathrm{O}$ model outputs for each reactor and model (a); total model efficiency and average efficiency (exponential expression) for dissolved and off-gas $\mathrm{N}_{2} \mathrm{O}$ model outputs related to the calibrated model (b) 
(a)

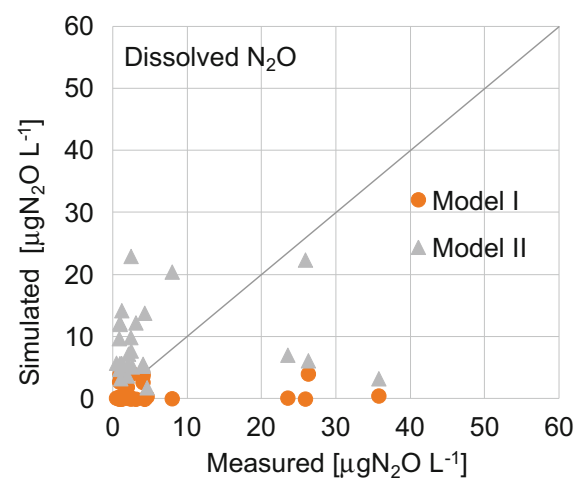

(b)

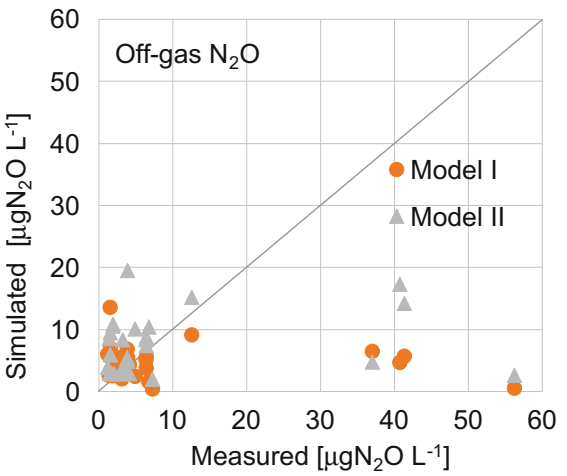

Fig. 2. Measured versus simulated data for calibrated Model I and Model II related to the dissolved (a) and Off-gas $\mathrm{N}_{2} \mathrm{O}$ (b)

Figure $1 \mathrm{~b}$ shows the total model efficiency $\left(\mathrm{E}_{\mathrm{MOD}}\right.$ ) and the average efficiency for both models in terms of $\mathrm{N}_{2} \mathrm{O}$. A general improvement of the efficiency of the dissolved $\mathrm{N}_{2} \mathrm{O}$ model outputs for non-aerated reactors (anaerobic and anoxic) and MBR has been obtained for the Model II (Fig. 1a). While, similar results were obtained in terms of Off-gas $\mathrm{N}_{2} \mathrm{O}$ model outputs (Fig. 1a). Data of Fig. $1 \mathrm{~b}$ confirm the general improvement of the calibrated Model II (respect to Model I) in terms of $\mathrm{N}_{2} \mathrm{O}$ model outputs. Indeed, the average model efficiency of the $\mathrm{N}_{2} \mathrm{O}$ model outputs increased from 0.3 (Model I) to 0.38 (Model II) (Fig. 1b).

For sake of completeness in Fig. 2 the measured versus simulated data for both dissolved (Fig. 2a) and off-gas $\mathrm{N}_{2} \mathrm{O}$ (Fig. 2b) in each reactor of the pilot plant are shown. A slight overestimation of simulated data occurred for the two models, expecting some cases, both for dissolved and off-gas $\mathrm{N}_{2} \mathrm{O}$. This result is likely debited to the discrete sampling. Continuous sampling would likely improve the results.

Table 1. Values of the coefficients adopted for comparison between Model I and Model II

\begin{tabular}{|c|c|c|c|c|c|c|c|c|c|c|c|}
\hline \multirow[t]{2}{*}{ Model } & \multirow[t]{2}{*}{ Coefficient } & \multicolumn{5}{|c|}{ Dissolved $\mathrm{N}_{2} \mathrm{O}$} & \multicolumn{4}{|c|}{ Off-gas $\mathrm{N}_{2} \mathrm{O}$} & \multirow[t]{2}{*}{$\mathrm{E}_{\mathrm{MOD}}$} \\
\hline & & Anaer & Anoxic & Aerobic & MBR & Perm & Anaer & Anoxic & Aerobic & MBR & \\
\hline \multirow[t]{4}{*}{ I } & $E_{\text {exp }}$ & 0.37 & 0.38 & 0.36 & 0.3 & 0.29 & 0.27 & 0.39 & 0.39 & 0.35 & \multirow[t]{4}{*}{0.55} \\
\hline & $N \& S$ & -0.3 & -0.06 & -0.34 & 0.63 & -1.17 & -0.3 & -0.09 & -0.11 & -0.15 & \\
\hline & $\mathrm{R}^{2}$ & 0.37 & 0.02 & 0.02 & 0.12 & 0.39 & 0.08 & 0.02 & 0.02 & 0.012 & \\
\hline & RSME & 0.013 & 0.009 & 0.009 & 0.01 & 0.013 & 0.021 & 0.014 & 0.013 & 0.014 & \\
\hline \multirow[t]{4}{*}{ II } & $E_{\text {exp }}$ & 0.32 & 0.43 & 0.32 & 0.4 & 0.27 & 0.29 & 0.4 & 0.39 & 0.45 & \multirow[t]{4}{*}{0.56} \\
\hline & $\mathrm{N} \& \mathrm{~S}$ & -0.13 & 0.04 & -0.59 & -1.16 & -1.54 & -0.16 & 0.26 & -0.06 & 0.2 & \\
\hline & $\mathrm{R}^{2}$ & 0.08 & 0.57 & 0.1 & 0.34 & 0.15 & 0.04 & 0.71 & 0.02 & 0.25 & \\
\hline & RSME & 0.013 & 0.008 & 0.01 & 0.012 & 0.014 & 0.02 & 0.011 & 0.012 & 0.012 & \\
\hline
\end{tabular}


Table 1 summarizes the results of the four coefficients adopted for evaluating the two models. Data of Table 1 confirm the general improvement of the results for Model II (respect to Model I) for $\mathrm{N}_{2} \mathrm{O}$ state variables for each estimated coefficient.

\section{Conclusions}

Two integrated MBR models which include GHGs as state variables have been compared. The two models mainly differ for the description of $\mathrm{N}_{2} \mathrm{O}$ production processes: Model I considers the $\mathrm{N}_{2} \mathrm{O}$ production only during denitrification; Model II, more detailed than Model I, considers the contribution of autotrophic biomass during $\mathrm{N}_{2} \mathrm{O}$ production considering both the ND and NN pathway. Model results showed a better capability of Model II in reproducing the measured data.

Acknowledgments. This work forms part of a research project supported by grant of the Italian Ministry of Education, University and Research (MIUR) through the Research project of national interest PRIN2012 (D.M. 28 dicembre 2012 n. 957/Ric - Prot. 2012PTZAMC) entitled "Energy consumption and GreenHouse Gas (GHG) emissions in the wastewater treatment plants: a decision support system for planning and management - http://ghgfromwwtp.unipa.it" in which the first author is the Principal Investigator.

\section{References}

Henze M, Gujer W, Mino T, Van Loosdrecht M (2000) Activated sludge models ASM1, ASM2, ASM2d and ASM3. In: IWA task group on mathematical modelling for design and operation of biological wastewater treatment. IWA Publishing, London

Hiatt WC, Grady CPL Jr (2008) An updated process model for carbon oxidation, nitrification, and denitrification. Water Environ Res 80:2145-2156

IPCC (2007) Changes in atmospheric constituents and in radiative forcing. In: Solomon S et al (eds.), Climate Change 2007: The physical science basis. contribution of working group I to the fourth assessment report of the intergovernmental panel on climate change. Cambridge University Press, Cambridge, pp 114-143

Jiang T, Myngheer S, De Pauw DJW, Spanjers H, Nopens I, Kennedy MD, Kennedy MD, Amy G, Vanrolleghem PA (2008) Modelling the production and degradation of soluble microbial products (SMP) in membrane bioreactors (MBR). Water Res 42(20):4955-4964

Kampschreur MJ, Kleerebezem R, de Vet WWJM, van Loosdrecht MCM (2011) Reduced iron induced nitric oxide and nitrous oxide emission. Water Res 45:5945-5952

Law Y, Ni B-J, Lant P, Yuan Z (2012) $\mathrm{N}_{2} \mathrm{O}$ production rate of an enriched ammonia-oxidising bacteria culture exponentially correlates to its ammonia oxidation rate. Water Res 46: 3409-3419

Mannina G, Cosenza A (2017) A new integrated MBR model including GHG emissions. Submitted to Environmental Science and Technology

Mannina G, Ekama G, Caniani D, Cosenza A, Esposito G, Gori R, Garrido-Baserba M, Rosso D, Olsson G (2016) Greenhouse gases from wastewater treatment - A review of modelling tools. Sci Total Environ 551-552:254-270 
Mannina G, Cosenza A (2015) Quantifying sensitivity and uncertainty analysis of a new mathematical model for the evaluation of greenhouse gas emissions from membrane bioreactors. J Membr Sci 475:80-90

Mannina G, Cosenza A, Vanrolleghem PA, Viviani G (2011) A practical protocol for calibration of nutrient removal wastewater treatment models. J Hydroinformatics 13(4):575-595

Nash JE, Sutcliff JV (1970) River flow forecasting through the conceptual model, Part 1: a discussion of principles. J Hydro 10(3):282-290

Ni B-J, Pan Y, van den Akker B, Ye L, Yuan Z (2015) Full-scale modeling explaining large spatial variations of nitrous oxide fluxes in a step-feed plug-flow wastewater treatment reactor. Environ Sci Technol 49:9176-9184

Ni BJ, Ye L, Law Y, Byers C, Yuan Z (2013) Mathematical modeling of nitrous oxide (N2O) emissions from full-scale waste water treatment plants. Environ Sci Technol 47(14):77957803

Peng L, Ni B-J, Ye L, Yuan Z (2015) Selection of mathematical models for N2O production by ammonia oxidizing bacteria under varying dissolved oxygen and nitrite concentrations. Chem Eng J 281:661-668

Pocquet M, Wu Z, Queinnec I, Spérandio M (2016) A two pathway model for $\mathrm{N}_{2} \mathrm{O}$ emissions by ammonium oxidizing bacteria supported by the NO/N2O variation. Water Res 88:948-959

Saltelli A, Tarantola S, Campolongo F, Ratto M (2004) Sensitivity analysis in practice. A guide to assessing scientific models, probability and statistics series. Wiley, Chichester

Spérandio M, Pocquet M, Guo L, Ni B-J, Vanrolleghem PA, Yuan Z (2016) Evaluation of different nitrous oxide production models with four continuous long-term wastewater treatment process data series. Bioprocess Biosyst Eng 39:493-510

Vanrolleghem PA, Rosen C, Zaher U, Copp J, Benedetti L, Ayesa E, Jeppsson U (2005) Continuity-based interfacing of models for wastewater systems described by Petersen matrices. Water Sci Technol 52:493-500 